of the paper seems to have been demanded by the Italian Air Ministry which had brought him into contact with the Caproni firm). Moreover, essential design features were given in patent specifications published before 1939.

I should like to add the critical remark that historic accounts of engineering development are not well based on interrogation reports compiled by teams who were professionally better equipped than linguistically. The mis-leading and contradictory impressions conveyed in many official reports on enemy progress are doubtless due to the interrogation of minor star performers whose faculty to speak English and whose eagerness to proffer information were obviously ill-matched by their professional abilities and by their modesty. In turn, this has led to some regrettable mistakes in selection.

A. R. Weyl, Associate Fellow.

\title{
A SUGGESTION FOR EXCHANGING INFORMATION
}

Many thanks for the List of Members recently received. I am sure that there must be many others similar to myself that have been away from the "Old Country" for many years, that have browsed through it and have found references to old friends and acquaintances of former years that have brought many nostalgic memories.

Having resided for a few years in Iraq, Egypt and Malta during my service with the R.A.F. several years ago, I have contemplated writing to some of the listed members in such far away places, to institute an exchange of aeronautical chats, as, from my own experience, I know that it can be a very lonely life, and the mail is a great thing to look forward to.

After all, one of the objects of the Society is "to promote the Species of Knowledge which distinguishes the Profession of Aeronautics," and what better way is there of accomplishing such spread of knowledge than an exchange of information between a member such as myself in an often sub-arctic atmosphere and a member in China or New Zealand, of which countries I must confess I know nothing of flying conditions.

Such a correlation of information I am sure would be very educational, and possibly could be compiled into many good joint articles for the JourNaL.

May I take the liberty of suggesting your devoting a small paragraph in the Monthly Notices or the Journal sometime, to this idea and see if any other members would be interested in instituting this correspondence scheme.

It would, I am sure, be very helpful for potential pilots and aircraft designers to know more about the geographical and meteorological conditions in foreign lands and would incidentally improve that camaraderie that should, and does, exist between all those who are interested in air transport.

667 Rielle Avenue, Verdun P.Q., Canada.

Thos. G. Cribb, M.I.Ae.S., A.R.Ae.S. 